\title{
Multi-Phase Modeling of Rainbird Water Injection
}

\author{
Bruce T. Vu* Nicholas Moss ${ }^{\dagger}$ Zoë Sampson ${ }^{\ddagger}$ \\ NASA Kennedy Space Center, FL 32899
}

\begin{abstract}
This paper describes the use of a Volume of Fluid (VOF) multiphase model to simulate the water injected from a rainbird nozzle used in the sound suppression system during launch. The simulations help determine the projectile motion for different water flow rates employed at the pad, as it is critical to know if water will splash on the first-stage rocket engine during liftoff.
\end{abstract}

\section{Introduction}

During the launch of the Space Shuttle several water suppression systems are used. These consist of the crest water nozzles mounted on the apex of the flame defector, Ignition Overpressure (IOP) water nozzles placed around the exhaust hole, and rainbird water nozzles installed above the launch deck (Figure 1). The rainbird water is specifically designed to suppress launch acoustics that can reflect from the flat surfaces of the deck. The Shuttle rainbirds were located on the North deck of the mobile launcher platform and were activated at T-0, so they didn't really pose a threat to Shuttle.

For the new Space Launch System (SLS) vehicle the operation is similar, regardless of the new mobile launcher and new engine configurations. The goal of the rainbird nozzle system remains the same, which is sound suppression (SS), and the rocket engines still cannot get wet. However, the rearrangement of the rainbird water system for the SLS mobile launcher, as shown in Figure 2, makes the rainbirds closer to the first-stage rocket engines, which are located above the exhaust hole and not shown in the Figure. The close proximity of the rainbird nozzle system could potentially cause vehicle wetting during liftoff.

This study is to complement the one-dimensional projectile calculation ${ }^{1}$ by considering the VOF multiphase. The objective of this study is to determine if the Shuttle-heritage rainbird system can be used for the SLS without water splashing on its rocket engines.

\section{Modeling}

The problem under study involves free surface with sharp interface between two fluids. All modeling reported in this paper was performed using OpenFOAM 2.3.0, an open source CFD software package developed by OpenCFD Ltd at ESI Group. ${ }^{2-4}$ Available solvers for problems involving two incompressible fluids with an interface are either laminar, Reynolds-Average Navier-Stokes (RANS) turbulence, and Large Eddy Simulation (LES). Only laminar and RANS solutions are reported in this study.

The problem considers the transient injection of water into an open space filled with air as shown in Figure 3. For simplicity we will consider only a two-dimensional case by assuming that the geometry has an infinite length in the z-direction. The rainbird nozzle with an exit diameter of $2.4 \mathrm{ft}$ is canted at a 10 degrees up and filled with water. At time zero, the water will be injected at an inlet velocity corresponding with a pre-determined volume flow rate. Table 1 lists the volume flow rates considered in the simulations for nomnial and abort operations.

The throw distances based 1-D projectile for the North corner, North center, and South rainbird nozzles are shown in Figures 4, 5, and 6, respectively. The water volume flow for the nominal operation is based on a maximum rainbird flow during $\mathrm{T}-20$ to $\mathrm{T}+20$ seconds, and the abort case is the same as T-zero.

*Lead, Fluid Systems Group, Senior Member AIAA.

$\dagger$ Ignition Overpressure and Sound Suppression Lead Design Engineer.

${ }^{\ddagger}$ Ignition Overpressure and Sound Suppression Systems Engineer. 


\begin{tabular}{|l||l|l|l|}
\hline \multicolumn{1}{|c||}{} & \multicolumn{2}{c|}{ Rainbird Nozzle System } \\
\hline Operation & North East/ North West & North Center & South East/ South West \\
\hline Nominal & 72,491 & 85,148 & 115,065 \\
Abort & 35,783 & 42,031 & 56,798 \\
\hline
\end{tabular}

Table 1. Water Flow Rates in GPM

\section{Governing Equations}

In the VOF method the same continuity and momentum equations are solved for both gas and liquid phases. The physical properties of one fluid are calculated as weighted averages based on the volume fraction of the two fluids in one cell. The conservation form of continuity and momentum equations are given by:

$$
\begin{gathered}
\nabla \cdot \mathbf{U}=0 \\
\frac{\partial \rho \mathbf{U}}{\partial t}+\nabla \cdot \rho \mathbf{U} \mathbf{U}-\nabla \cdot \mu \nabla \mathbf{U}-\rho g=-\nabla p-S_{s}
\end{gathered}
$$

where $S_{s}$ is the surface tension which takes place only at the free surfaces.

The volume of fluid in a cell is computed as $V=\alpha V_{\text {cell }}$, where $V_{\text {cell }}$ is the volume of a computational cell and $\alpha$ is the fluid fraction in a cell. If the cell is completely filled with water then $\alpha=1$ and if it is filled with air then its value should be 0 . At the interface the value of $\alpha$ is between 0 and 1 . The phase fraction $\alpha$ can be computed from a separate transport equation that is given by:

$$
\frac{\partial \alpha}{\partial t}+\nabla \cdot \alpha \mathbf{U}=0
$$

A convective term is added to take into account of the compression of the surface, leading to a countergradient transport equation as follows:

$$
\frac{\partial \alpha}{\partial t}+\nabla \cdot \alpha \mathbf{U}+\nabla \cdot \alpha(1-\alpha) \mathbf{U}_{\mathbf{c}}=0
$$

where $\mathbf{U}_{\mathbf{c}}$ is a velocity field suitable to compress the interface.

The density and viscosity in the domain are calculated as a weighted average of the volume fraction of the two fluids, $\alpha$, as follows:

$$
\begin{aligned}
& \rho=\alpha \rho_{1}+(1-\alpha) \rho_{2} \\
& \mu=\alpha \mu_{1}+(1-\alpha) \mu_{2}
\end{aligned}
$$

The surface tension $S_{s}$ on the RHS of the momentum equation is given by:

$$
S_{s}=\sigma K \nabla \alpha
$$

$K$ is the curvature of the interface and is calculated by:

$$
K=-\nabla \cdot \hat{n}
$$

where $\hat{n}$ is the normal unit vector based on the volume fraction $\alpha$ :

$$
\hat{n}=\frac{\nabla \alpha}{|\nabla \alpha|}
$$




\section{Discussion of Results}

Figure 7 shows the structured mesh generated using blockMesh utility available in the OpenFOAM package. The same topology is used for both nominal and abort operations, except that the computational width is shorter in the abort case because of the shorter throw distance. The grading of the mesh can be easily modified to resolve the boundary layers close to the walls. However, this is not an important feature since the focus is on the actual distance traveled by the water jet.

Figures 8-10 show the volume fraction of water $(\alpha)$ after $5 \mathrm{sec}$ from the start of the injection for the higher volume flow rate associated with nominal operation; the red color corresponds to $\alpha=1$, which is water and blue corresponding to $\alpha=0$, which is air. It can be seen that water stream has traveled $11 \mathrm{~m}, 13 \mathrm{~m}$, and $18.5 \mathrm{~m}$ for the North corner, North center, and South rainbirds, respectively. These values closely match those depicted by the 1-D projectile calculation $(11.9 \mathrm{~m}, 14.6 \mathrm{~m}$, and $21.4 \mathrm{~m})$. The slight overprediction by the projectile analysis is due to the fact that it neglected the air resistance effect, which is accounted for in the multi-phase modeling.

Figures 11-13 show the velocity field for three rainbird nozzles during nominal operation. It is obvious that these simultions exhibit two different flow patterns. While the distance traveled can be approximated using these velocity contours and the results are in agreement with those obtained from the volume fraction contours, the high flow rate shows a less accumulation of water on the deck. For the lower volume flow rate, the recirculation zone is smaller and the flow is more diffusive at the impingement location.

The contours of water volume fraction and velocity magnitude for the abort case can be found in Figures 14-19. Similar conclusions can be drawn regarding the flow behaviors. Again, the throw distances are slightly overpredicted by the projectile calculation compared to multi-phase modeling; the distance traveled as predited by the VOF simulations are $5.2 \mathrm{~m}, 6 \mathrm{~m}$, and $8 \mathrm{~m}$ for North corner, North center, and South rainbirds, compared to $5.3 \mathrm{~m}, 6.4 \mathrm{~m}$, and $8.9 \mathrm{~m}$ from Figures $4-6$. It should be noted that the laminar flow solution for the abort case is very dispersive. The turbulent diffusion solution was obtained using a k- $\epsilon$ turbulence model and presented in the abort case. The throw distances for all rainbird nozzles operated under nominal and abort conditions are summarized in Table 2.

\begin{tabular}{|c|c|c|c|c|c|c|}
\hline & \multicolumn{3}{|c|}{ Throw Distance (Nominal) } & \multicolumn{3}{|c|}{ Throw Distance (Abort) } \\
\hline $\begin{array}{l}\text { Analysis } \\
\text { Model }\end{array}$ & $\begin{array}{l}\text { North East/ } \\
\text { North West }\end{array}$ & $\begin{array}{l}\text { North } \\
\text { Center }\end{array}$ & $\begin{array}{l}\text { South East / } \\
\text { South West }\end{array}$ & $\begin{array}{l}\text { North East/ } \\
\text { North West }\end{array}$ & $\begin{array}{l}\text { North } \\
\text { Center }\end{array}$ & $\begin{array}{l}\text { South East / } \\
\text { South West }\end{array}$ \\
\hline $\begin{array}{l}\text { 1-D Projectile } \\
\text { Multi-phase }\end{array}$ & $\begin{array}{l}11.9 \mathrm{~m} \\
11.0 \mathrm{~m}\end{array}$ & $\begin{array}{l}14.6 \mathrm{~m} \\
13.0 \mathrm{~m}\end{array}$ & $\begin{array}{l}21.4 \mathrm{~m} \\
18.5 \mathrm{~m}\end{array}$ & $\begin{array}{l}5.3 \mathrm{~m} \\
5.2 \mathrm{~m}\end{array}$ & $\begin{array}{l}6.4 \mathrm{~m} \\
6.0 \mathrm{~m}\end{array}$ & $\begin{array}{l}8.9 \mathrm{~m} \\
8.0 \mathrm{~m}\end{array}$ \\
\hline
\end{tabular}

Table 2. Comparison of Throw Distances

Both projectile and VOF predictions indicate that in the abort case the water jet stream from a rainbird nozzle will not reach the rocket engine. Likewise, during nominal operation it might appear that water jet from the rainbird operated at higher flow rates might reach the core stage. However, the vehicle starts to move before the water jet reaches fully-developed flow; therefore, water impingement on the vehicle is unlikely. A detailed three-dimensional VOF or smoothed particle hydrodynamics (SPH) analysis ${ }^{5-8}$ could be helpful in studying such transient phenomenon.

\section{Conclusion}

The 2-D VOF simulation has been used to determine the throw distances by the rainbird water nozzle system. It provides a less conservative prediction as compared to 1-D projectile analysis, thus allowing design margins to be reduced. In general, there is good agreement between the two analyses for the short throw distances. The discrepancies are greater for long throw distances, in which air resistance and drag dominated flows are more significant. The IOP/SS engineers have several design options in case the rainbird water injection system could wet rocket engines during launch. These options include lowering the rainbird nozzle, adjusting the flow rates, or changing its injection angle. Further study using three-dimensional VOF or SPH might be required to determine if Shuttle-derived rainbirds can meet the requirement of sound suppression while keeping the SLS rocket engines and other sensitive ground support elements dry during nominal launch and pad abort operations. 


\section{Acknowledgement}

The first author would like to thank Dr. Chris Greenshield at ESI group for the OpenFOAM training. The rainbird water nozzle redesign project was supported by the KSC Ground Support and Development Operations (GSDO) office, with Mr. Eric Ernst as the Mobile Launcher program manager.

\section{References}

${ }^{1}$ Moss, Nick and Sampson, Zoë, "Rainbird Water Throws," KSC Internal Study, 27 June 2013.

${ }^{2}$ C.J. Greenshields, H.G. Weller, and A. Ivankovic, "The finite volume method for coupled fluid flow and stress analysis," Computer modelling and simulation in engineering, 4:213-218, 1999.

${ }^{3}$ Jasak, H.; Tukovic, Z.; Jemcov, A., "OpenFOAM: A C++ Library for Complex Physics Simulations," Coupled Methods in Numerical Dynamics, 2007.

${ }^{4}$ Suraj S. Deshpande, Lakshman Anumolu, Mario F. Trujillo, "Evaluating the performance of the two-phase flow solver interFoam," Computational Science \& Discovery, Vol. 5, No. 1. (01 January 2012)

${ }^{5}$ Bruce Vu, Jared Berg, and Michael Harris, "Launch Environment Water Flow Simulation Using Smoothed Particle Hydrodynamics (SPH)," Applied Modeling and Simulation (AMS) seminar, NASA Ames Research Center, 18 April 2014.

${ }^{6}$ Crespo AJC, Dominguez JM, Barreiro A, Gmez-Gesteira M and Rogers BD, 2011, "GPUs, a new tool of acceleration in CFD: Efficiency and reliability on Smoothed Particle Hydrodynamics methods, PLoS ONE. doi:10.1371/journal.pone.0020685.

${ }^{7}$ B.D. Rogers, "Developing smoothed particle hydrodynamics (SPH) on CUDA work by the SPHysics group, School of Mechanical, Aerospace and Civil Engineering (MACE), University of Manchester, UK.

${ }^{8}$ G.R. Liu, "Smoothed Particle Hydrodynamics: A Meshfree Particle Method, World Scientific, ISBN-13: 978-9812384560. 


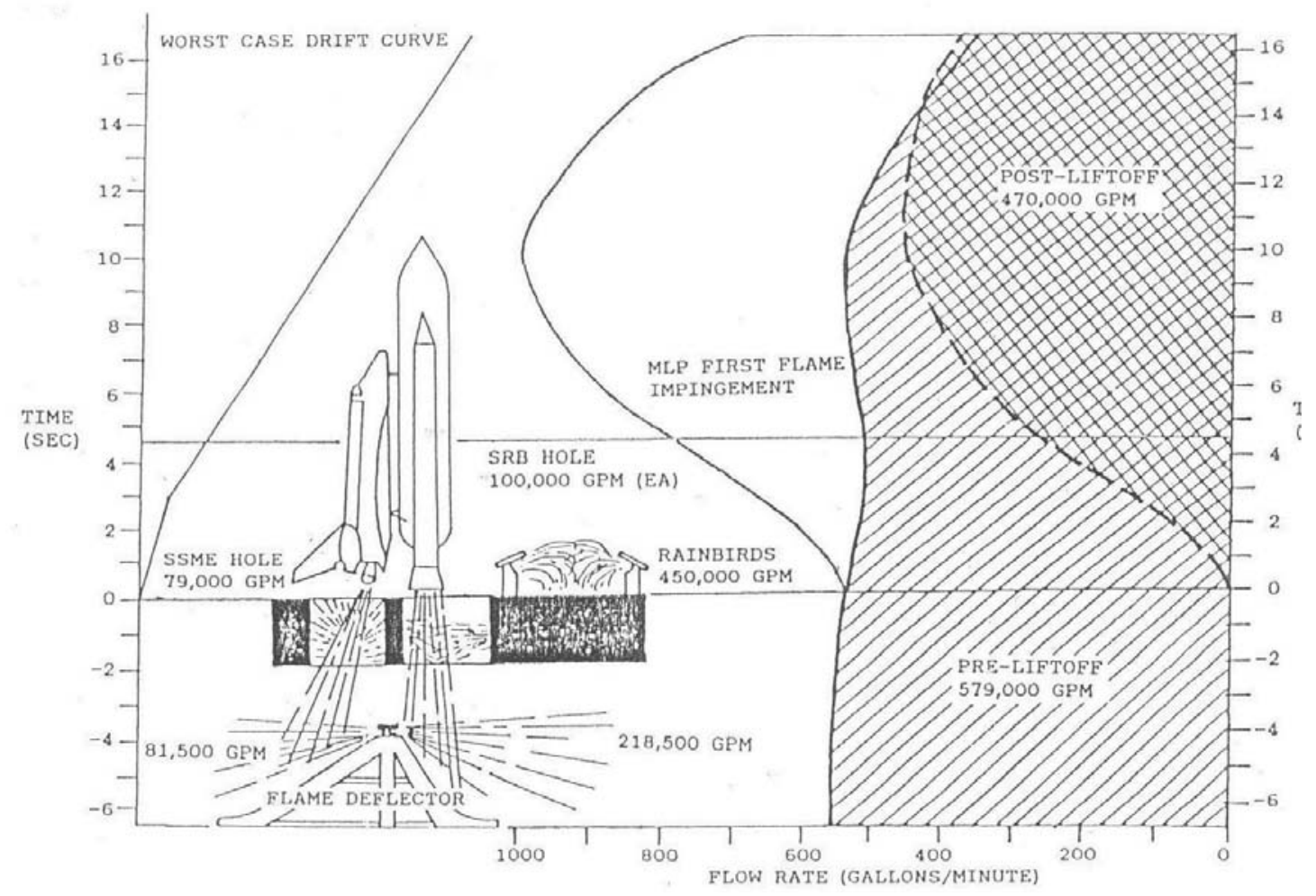

Figure 1. Shuttle Water Sound Suppression System.

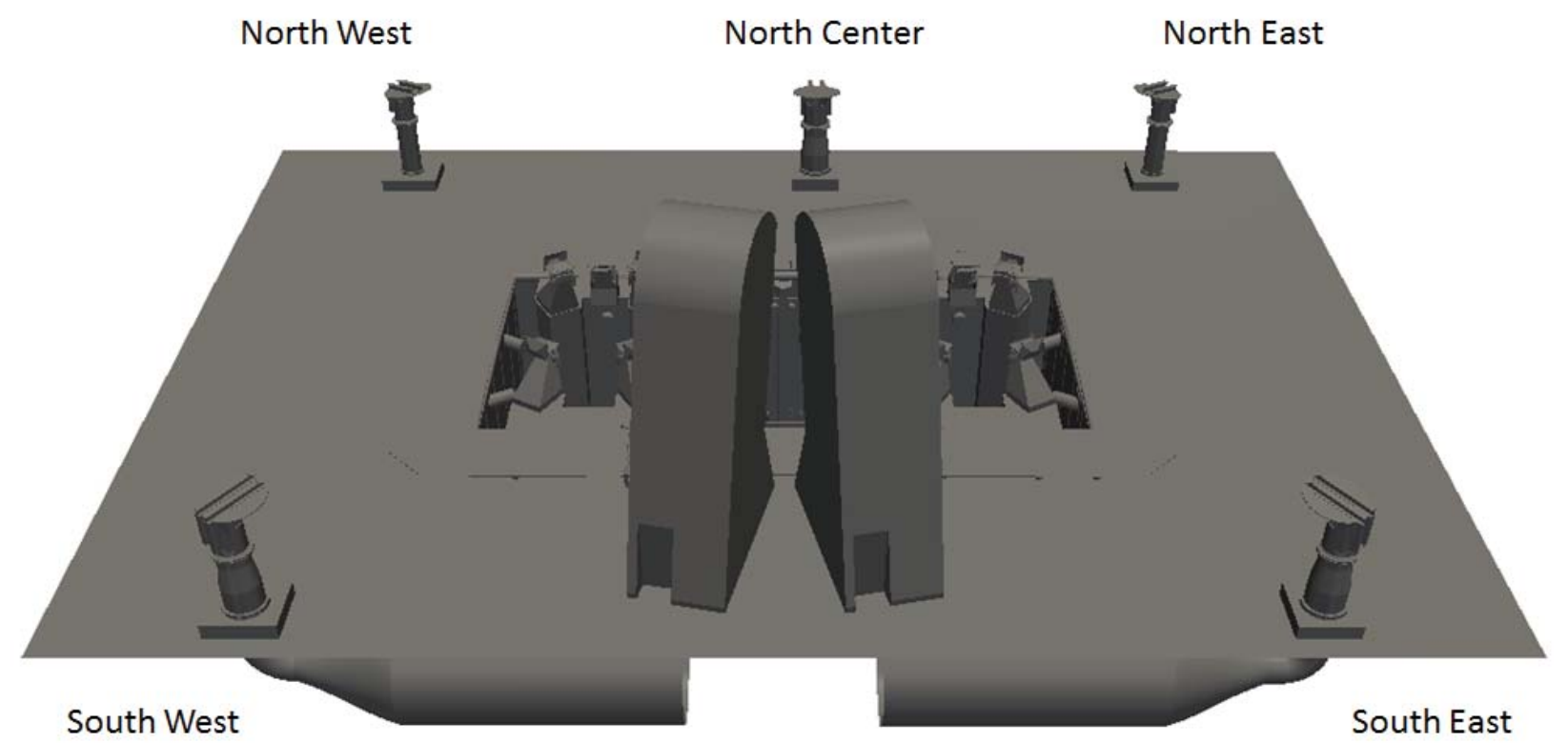

Figure 2. SLS Rainbird Nozzle System. 


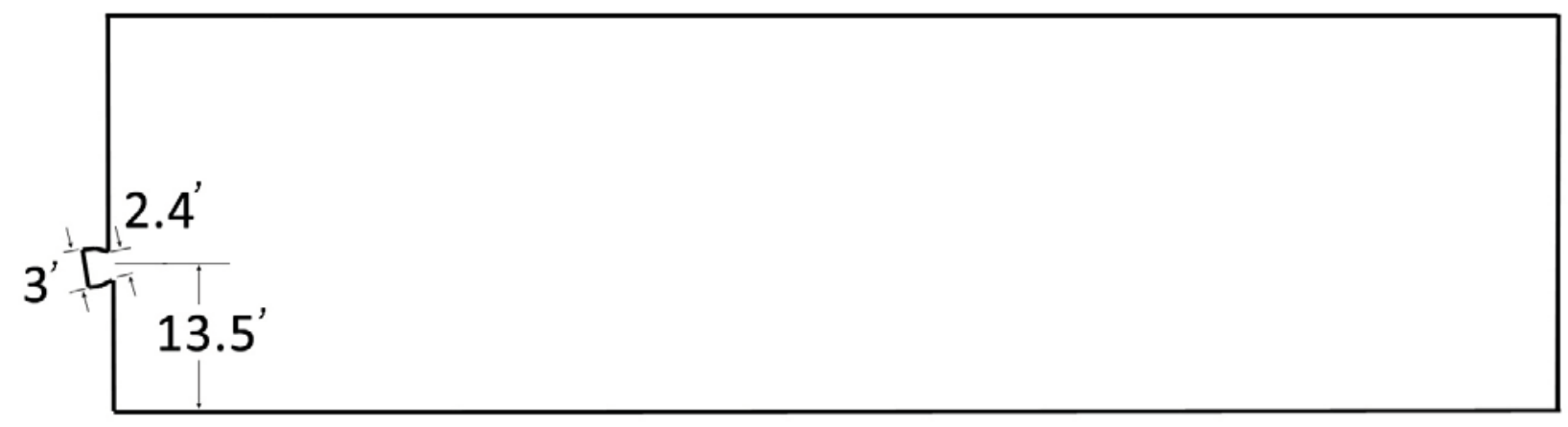

Figure 3. Geometry Setup.

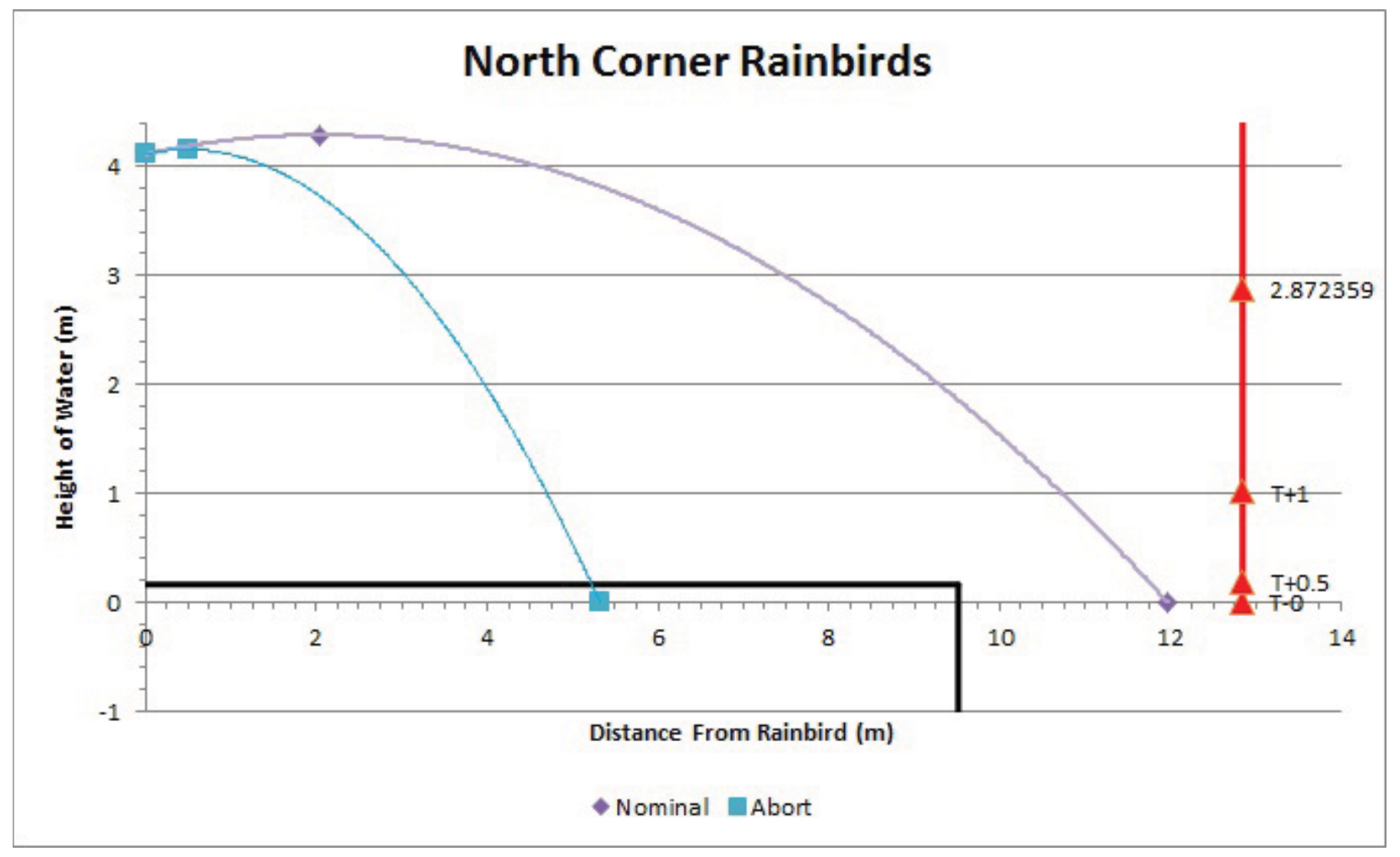

Figure 4. 1-D Projectile Prediction (North Corner). 


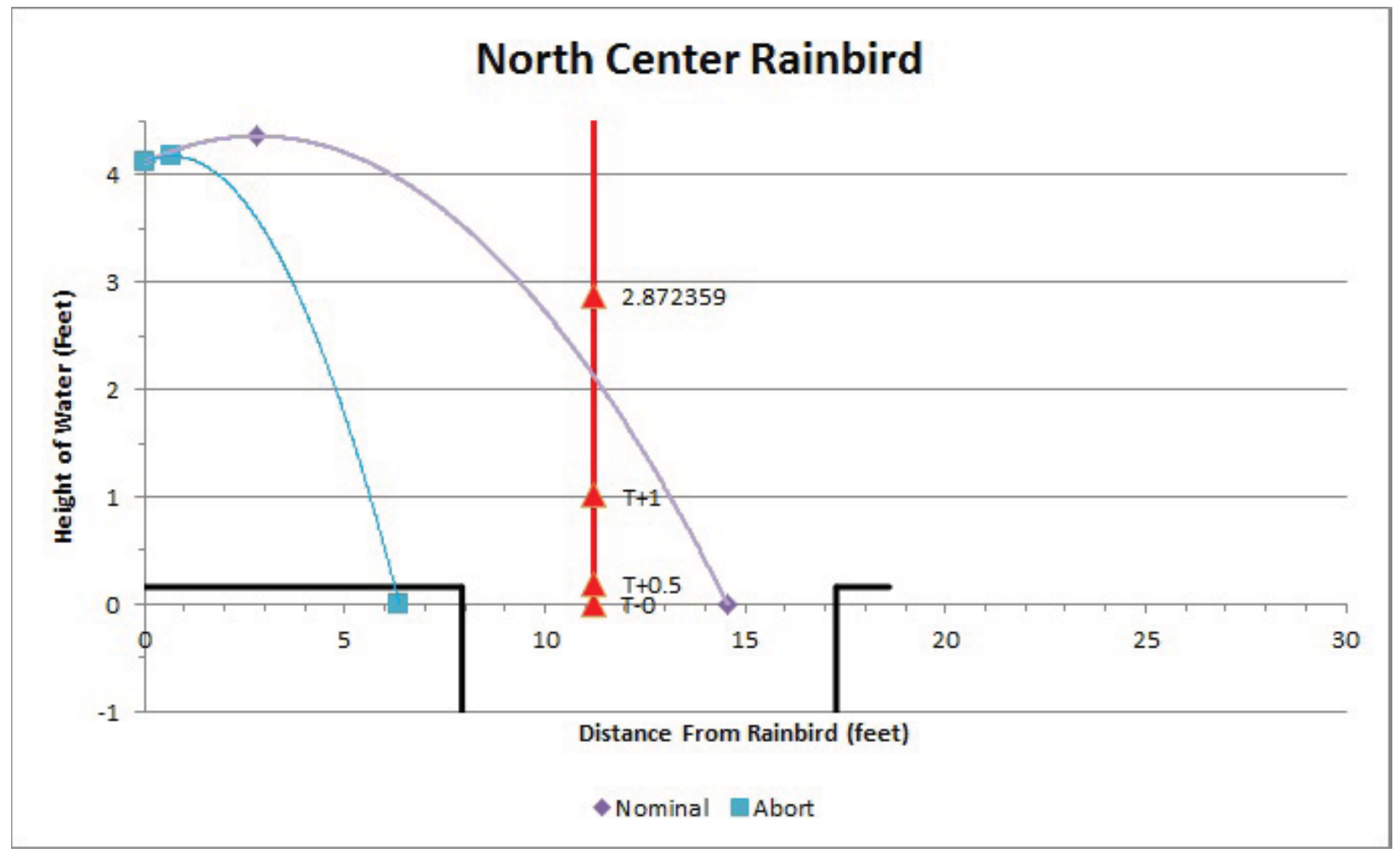

Figure 5. 1-D Projectile Prediction (North Centerr).

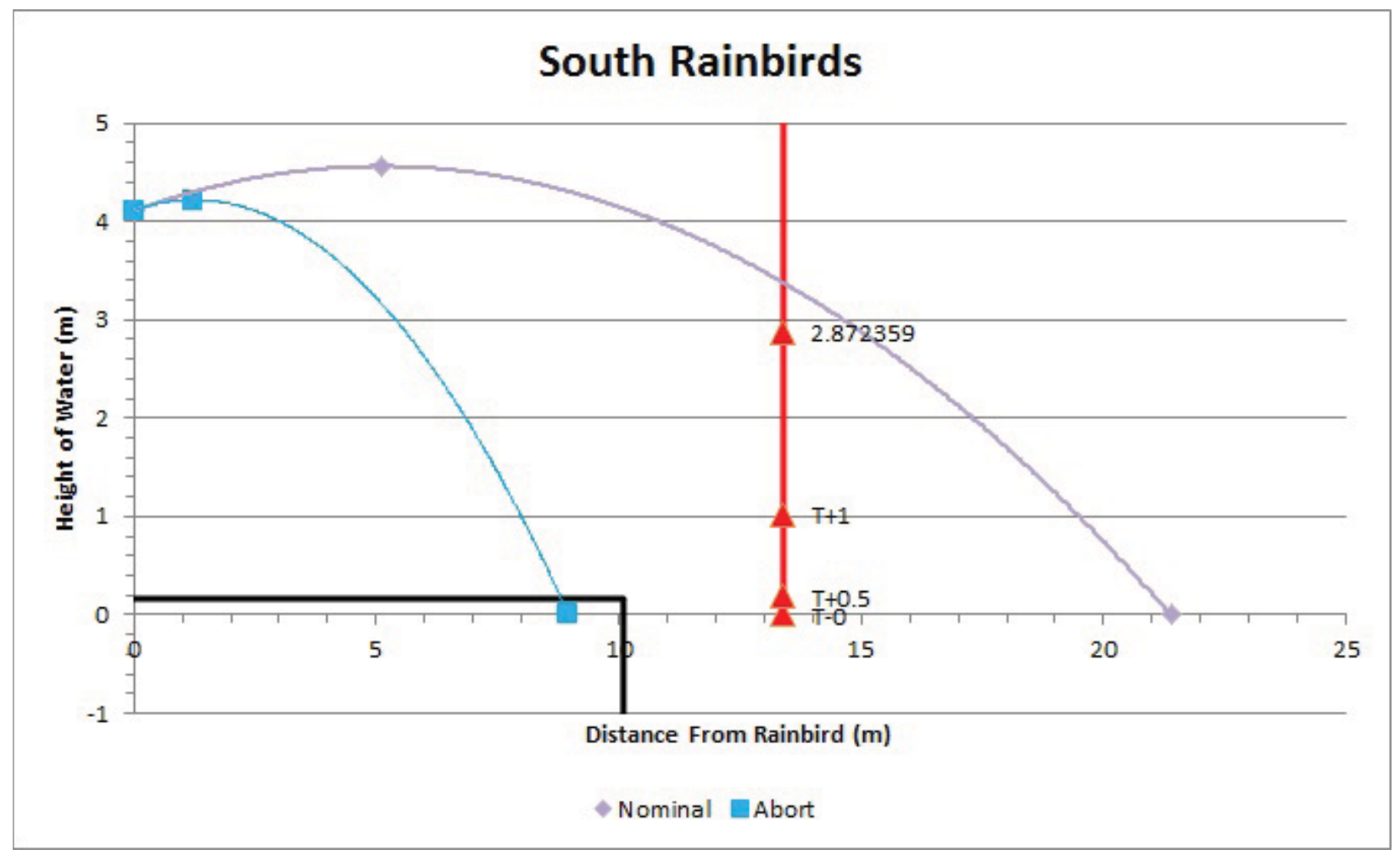

Figure 6. 1-D Projectile Prediction (South). 


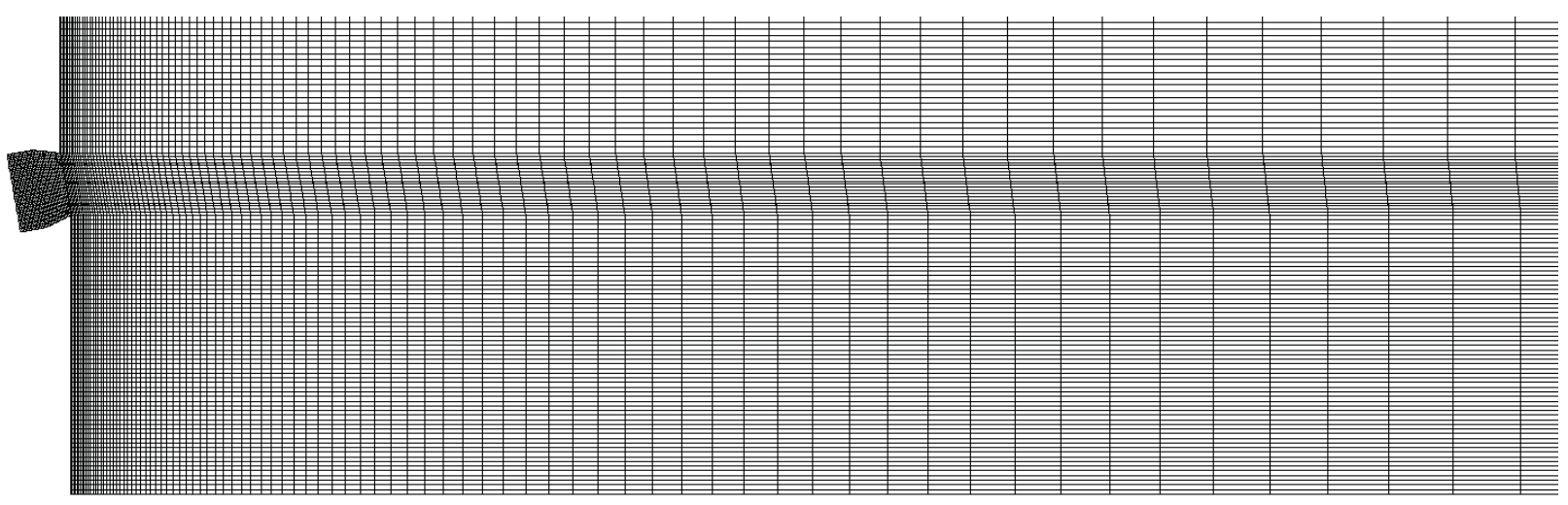

Figure 7. Computatioal Mesh.

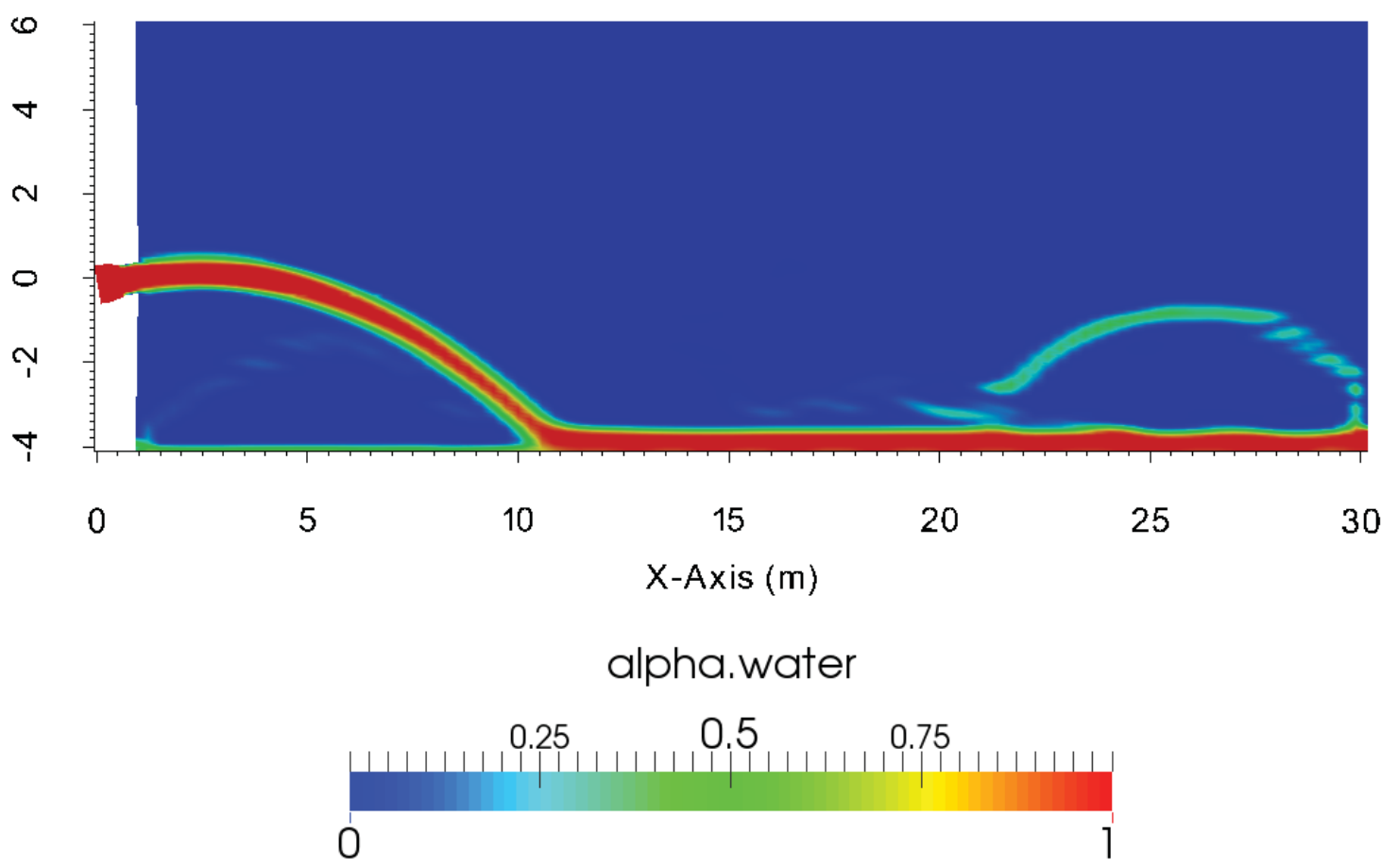

Figure 8. Water Volume Fraction for North Corner Rainbird (Nominal - 72,491 GPM). 


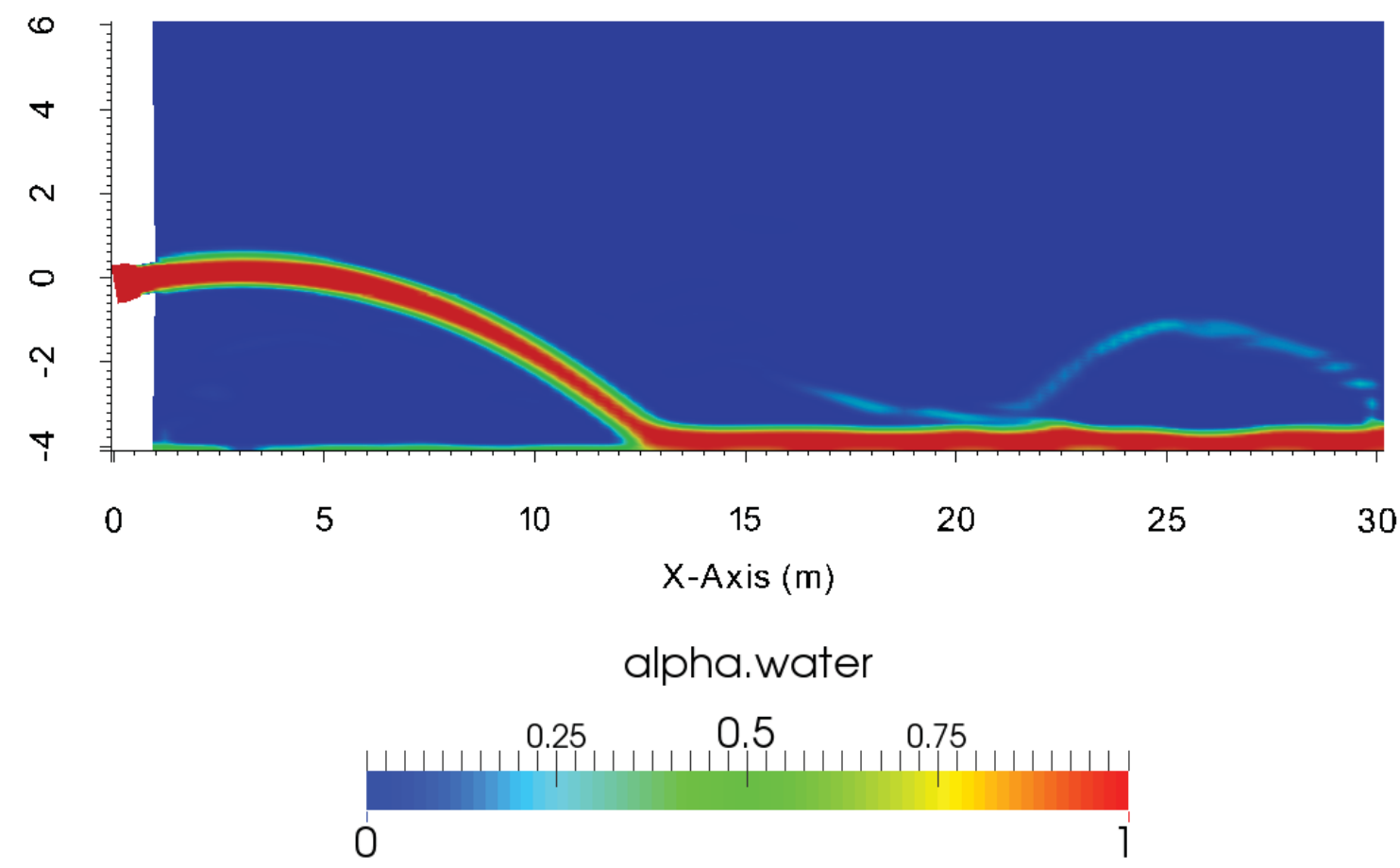

Figure 9. Water Volume Fraction for North Center Rainbird (Nominal - 85,148 GPM).

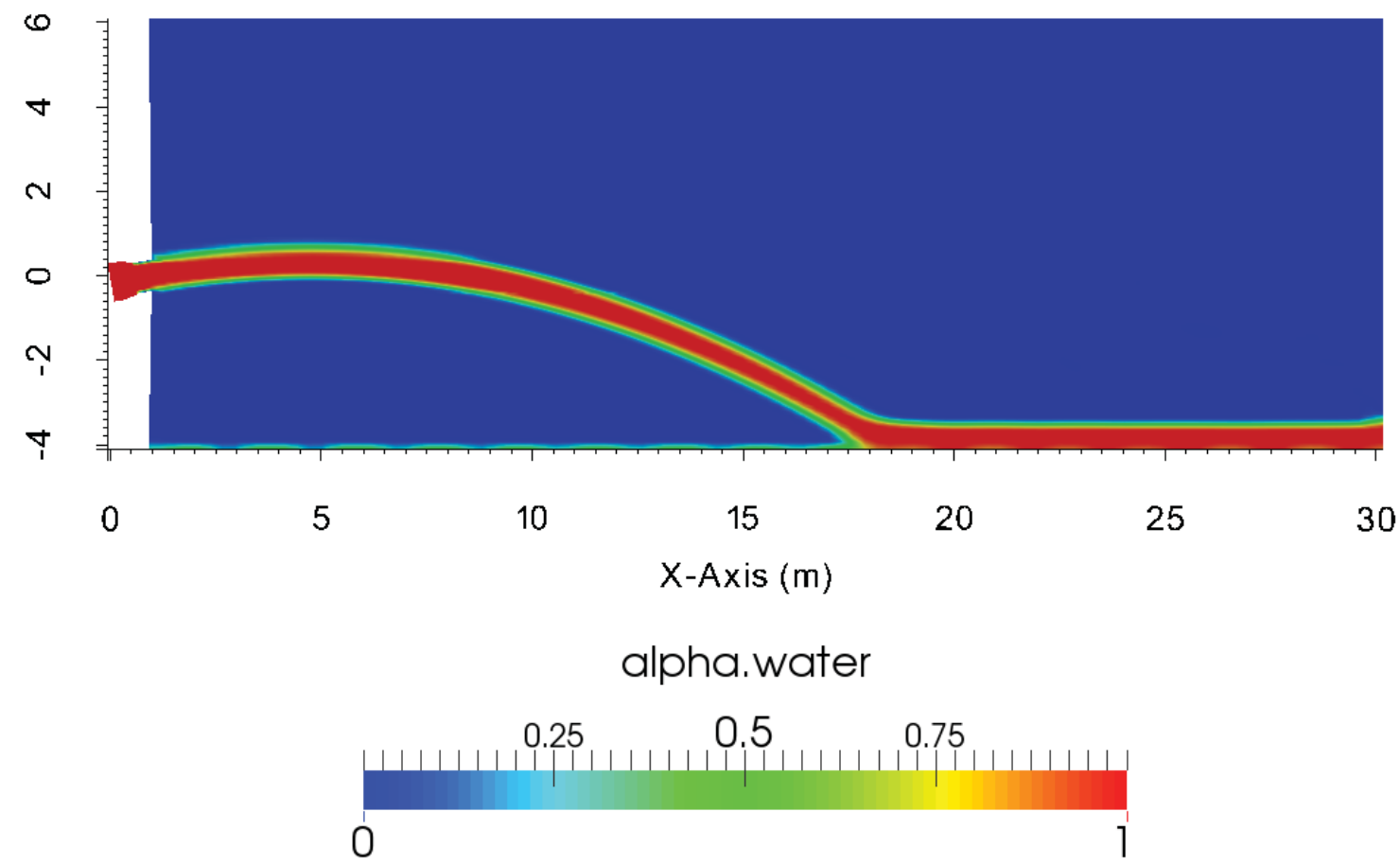

Figure 10. Water Volume Fraction for South Rainbird (Nominal - 115,065 GPM). 


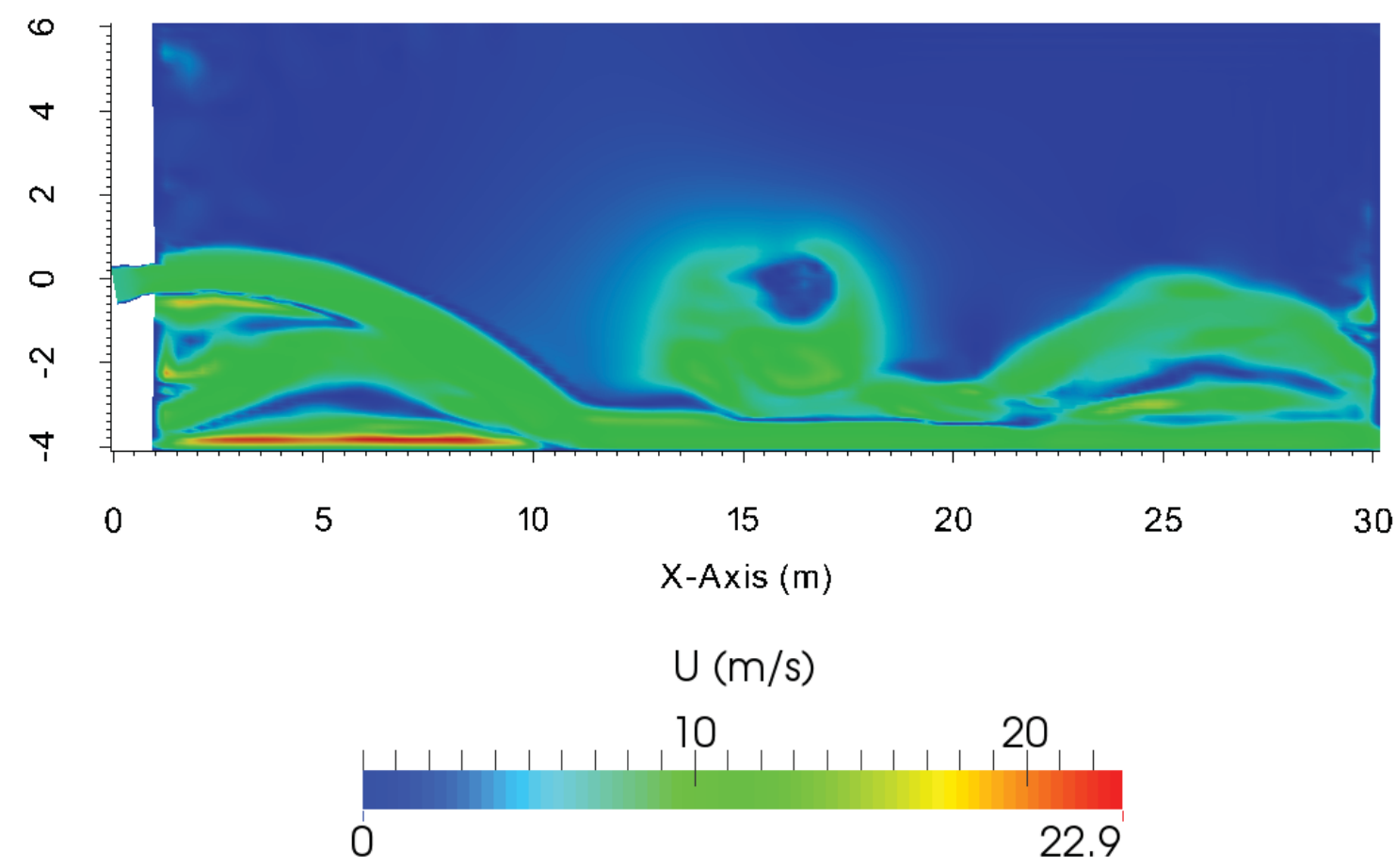

Figure 11. Velocity Magnitude for North Corner Rainbird (Nominal - 72,491 GPM).

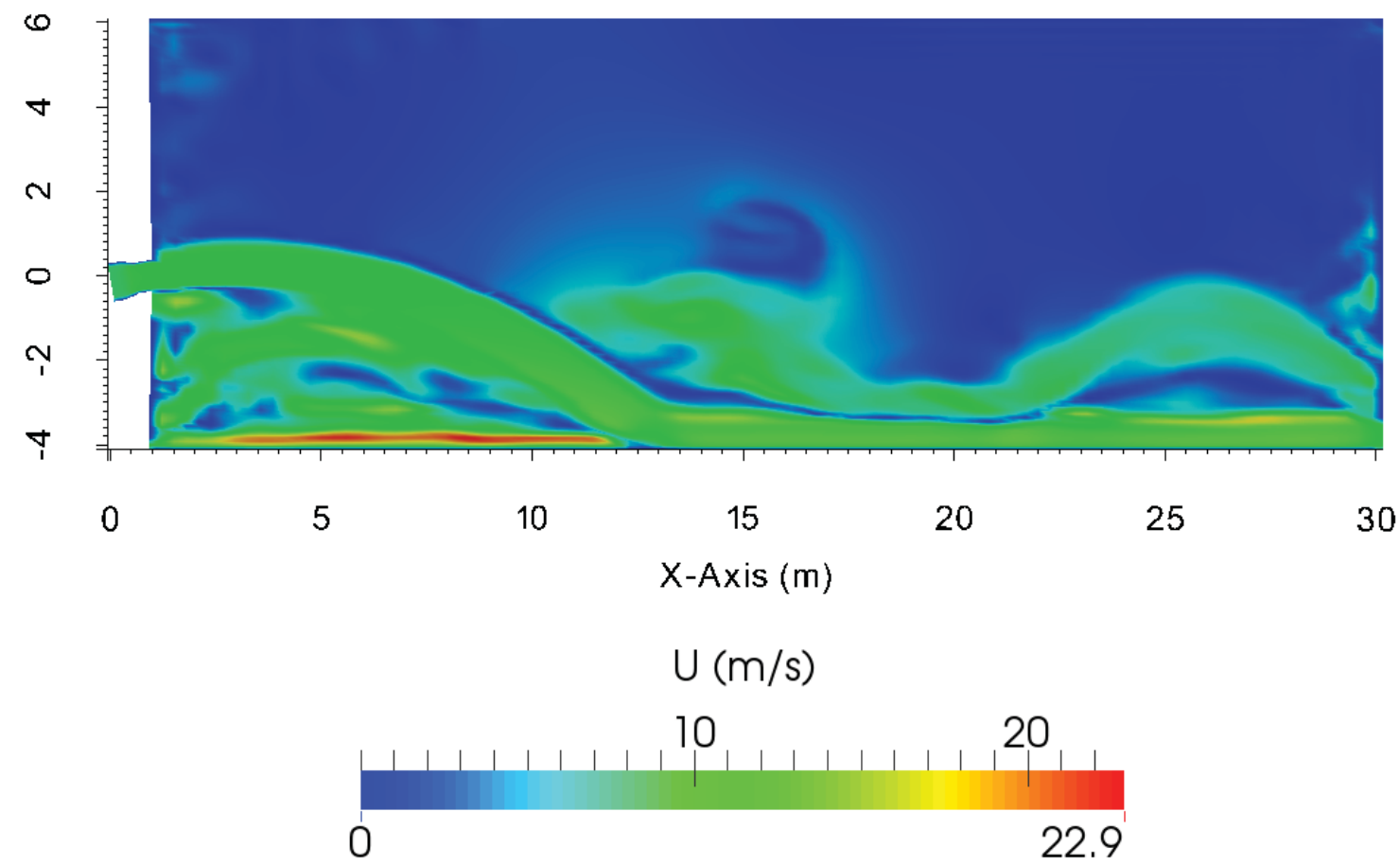

Figure 12. Velocity Magnitude for North Center Rainbird (Nominal - 85,148 GPM). 


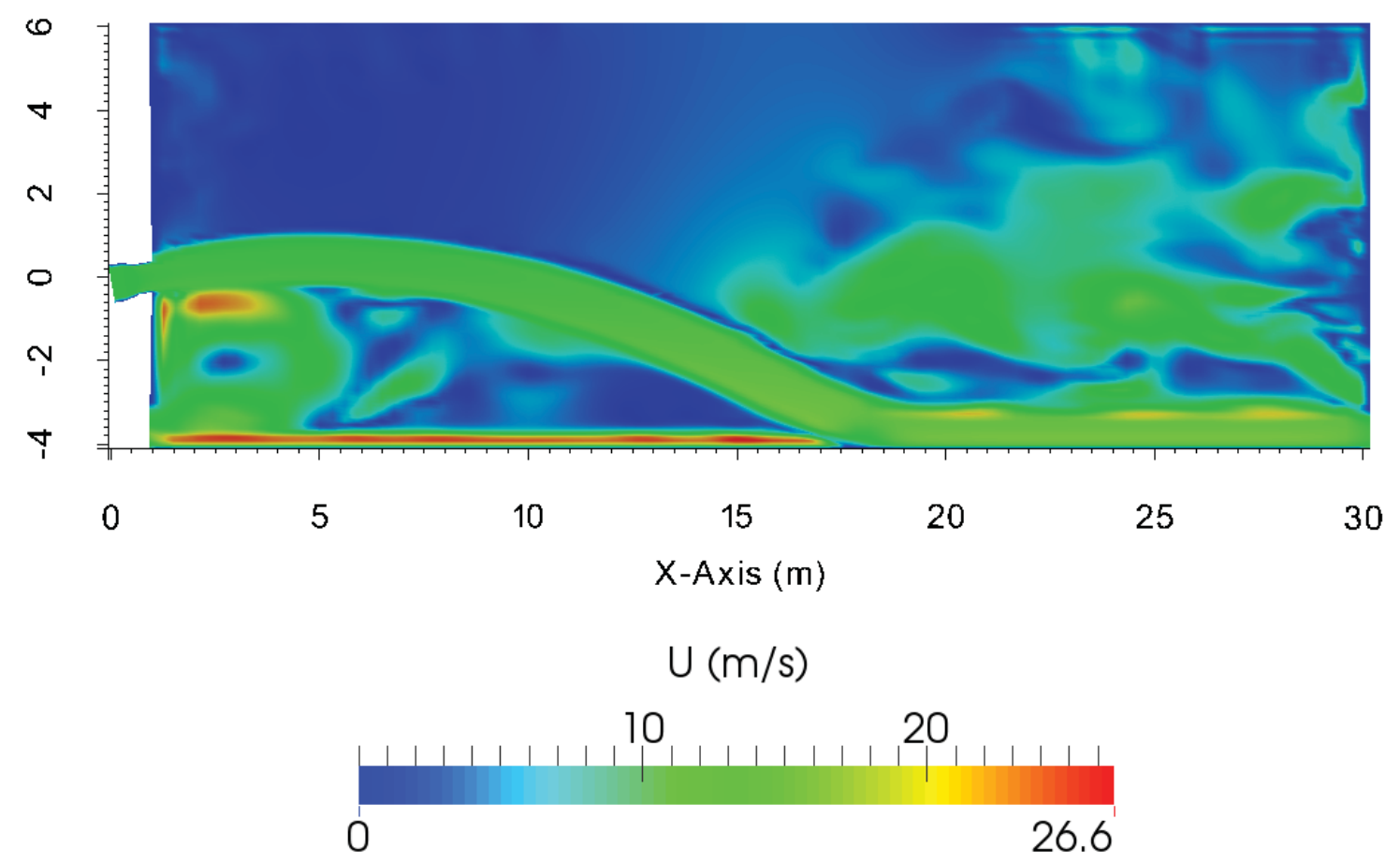

Figure 13. Velocity Magnitude for South Rainbird (Nominal - 115,065 GPM).
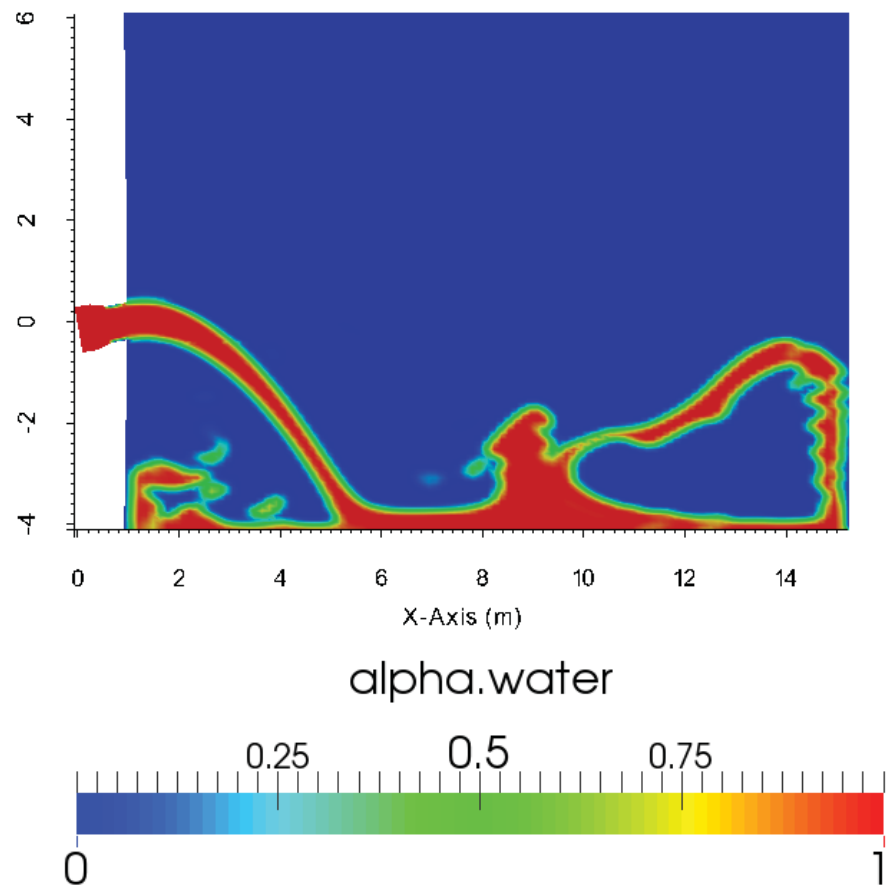

Figure 14. Water Volume Fraction for North Corner Rainbird (Abort - 35,783 GPM). 


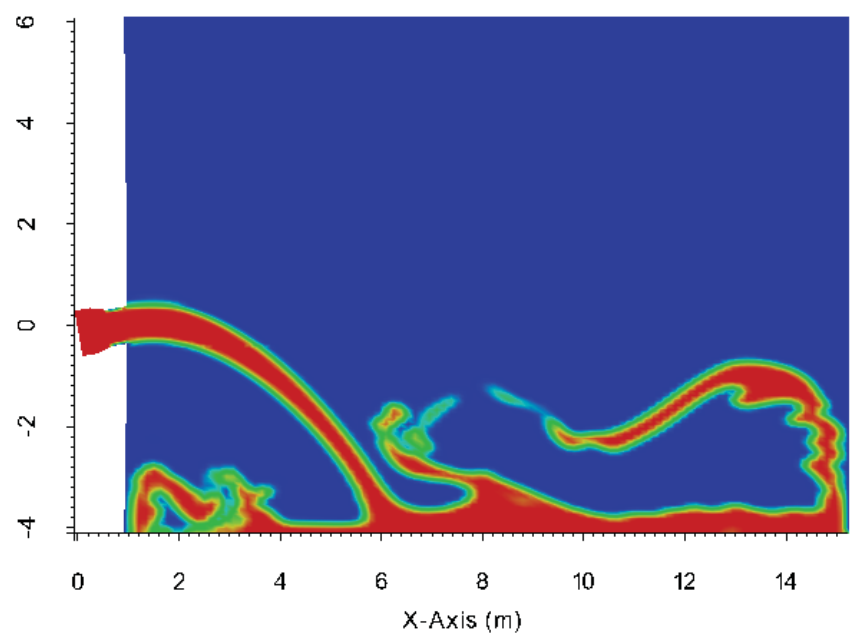

alpha.water

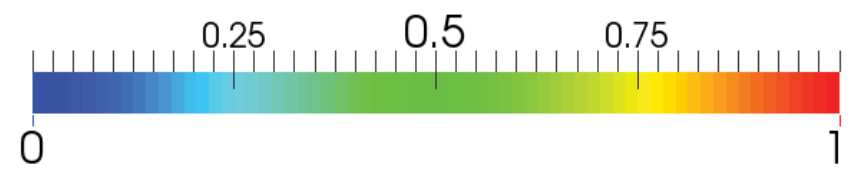

Figure 15. Water Volume Fraction for North Center Rainbird (Abort - 42,031 GPM).

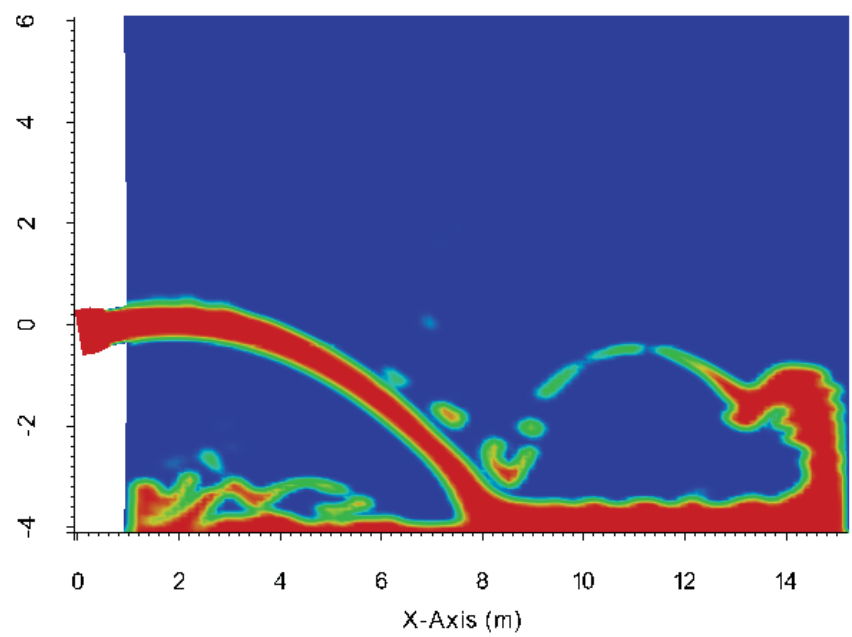

\section{alpha.water}

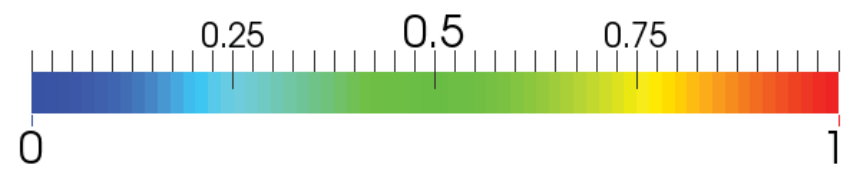

Figure 16. Water Volume Fraction for South Rainbird (Abort - 56,798 GPM). 


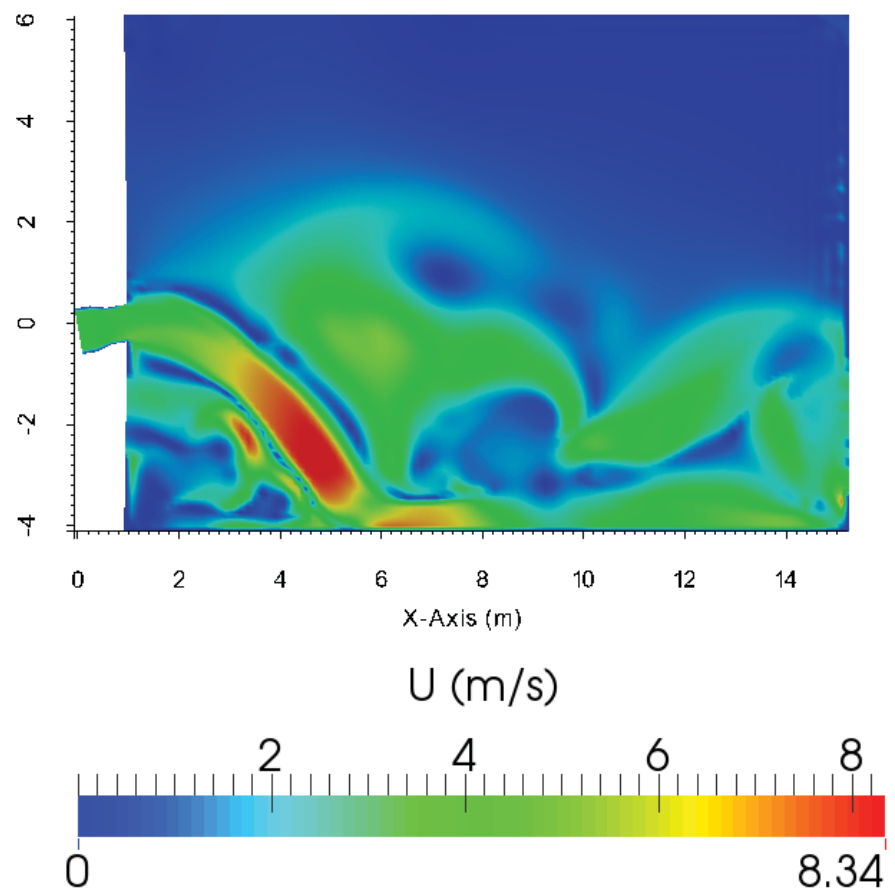

Figure 17. Velocity Magnitude for North Corner Rainbird (Abort -35,783 GPM).

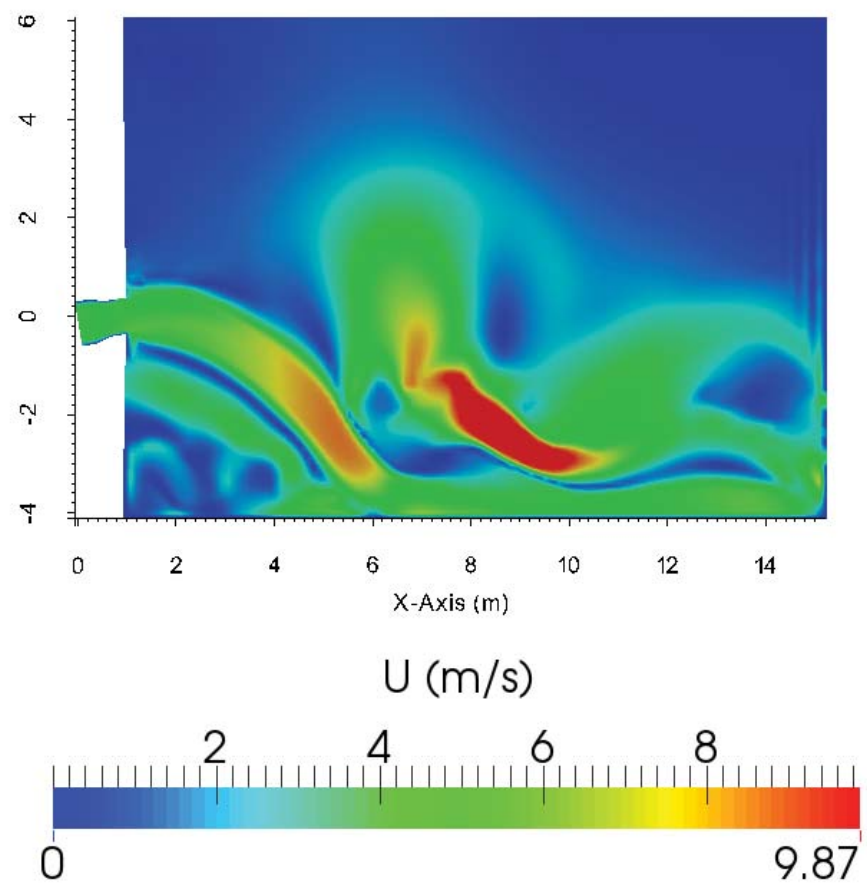

Figure 18. Velocity Magnitude for North Center Rainbird (Abort - 42,031 GPM). 


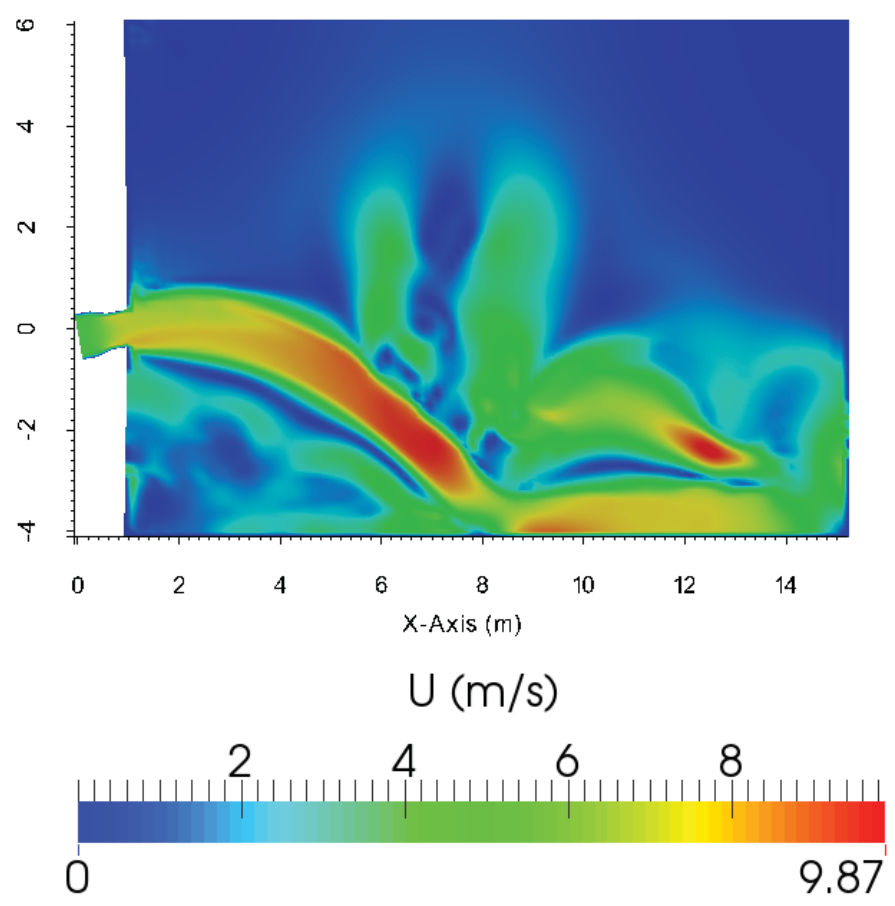

Figure 19. Velocity Magnitude for South Rainbird (Abort - 56,798 GPM). 